\title{
Seasonal dispersal and longitudinal migration in the Relict Gull Larus relictus across the Inner-Mongolian Plateau
}

\author{
Dongping Liu ${ }^{1}$, Guogang Zhang ${ }^{\text {Corresp.. }}{ }^{1}$, Hongxing Jiang ${ }^{1}$, Lixia Chen ${ }^{1}$, Derong Meng ${ }^{2}$, Jun Lu ${ }^{1}$ \\ ${ }^{1}$ Key Laboratory of Forest Protection of State Forestry Administration, Research Institute of Forest Ecology and Environment Protection, Chinese Academy \\ of Forestry, Beijing, China \\ 2 Cangzhou Normal University, Cangzhou, China \\ Corresponding Author: Guogang Zhang \\ Email address: zm7672@caf.ac.cn
}

The Relict Gull Larus relictus is a globally vulnerable species and one of the least known birds, so understanding its seasonal movements and migration will facilitate the development of effective conservation plans for its protection. We repeatedly satellite tracked 11 adult Relict Gulls from the Ordos sub-population in Hongjian Nur, China, over 33 migration seasons and conducted extensive ground surveys. Relict Gulls traveled $\sim 800$ $\mathrm{km}$ between Hongjian Nur in northern China to the coast of eastern China in a predominantly longitudinal migration, following a clockwise loop migration pattern. The gulls migrated faster in spring ( $4 \pm 2 \mathrm{~d}$ ) than in autumn (15 $\pm 13 \mathrm{~d}$ ) due to a timeminimization strategy for breeding, and they showed considerable between-individual variation in the timing of the autumn migration, probably due to differences in the timing of breeding. Gulls that made at least two round trips exhibited high flexibility in spring migration timing, suggesting a stronger influence of local environment conditions over endogenous controls. There was also high route flexibility among different years, probably due to variations in meteorological or habitat conditions at stopover sites. Relict Gulls stayed for a remarkably long time ( $234 \pm 17 \mathrm{~d}$ ) on their major wintering grounds in Bohai Bay and Laizhou Bay, between which there were notable dispersals. Pre-breeding dispersals away from the breeding area were distinct, which seemed to be a strategy to cope with the degradation of breeding habitat at Hongjian Nur. Overwhelming lake shrinkage on the breeding ground and at stopover sites and loss of intertidal flats on the wintering grounds are regarded as the main threats to Relict Gulls. It's crucial to make protection administrations aware of the great significance of key sites along migration routes and to promote the establishment of protected areas in these regions. 
1 Seasonal dispersal and longitudinal migration in the Relict Gull Larus relictus across the

2 Inner-Mongolian Plateau

3 Dongping Liu ${ }^{1}$, Guogang Zhang ${ }^{1 *}$, Hongxing Jiang ${ }^{1}$, Lixia Chen ${ }^{1}$, Derong Meng ${ }^{2}$, Jun Lu ${ }^{1}$

$4{ }^{1}$ Key Laboratory of Forest Protection of State Forestry Administration, Research Institute of

5 Forest Ecology and Environment Protection, Chinese Academy of Forestry, Beijing, China

$6 \quad{ }^{2}$ Cangzhou Normal University, Cangzhou, China

7 Corresponding Author: Guogang Zhang

8 Email address: zm7672@caf.ac.cn

9 ABSTRACT

10 The Relict Gull Larus relictus is a globally vulnerable species and one of the least known birds, 11 so understanding its seasonal movements and migration will facilitate the development of 12 effective conservation plans for its protection. We repeatedly satellite tracked 11 adult Relict 13 Gulls from the Ordos sub-population in Hongjian Nur, China, over 33 migration seasons and 14 conducted extensive ground surveys. Relict Gulls traveled $800 \mathrm{~km}$ between Hongjian Nur in northern China to the coast of eastern China in a predominantly longitudinal migration, following a clockwise loop migration pattern. The gulls migrated faster in spring $(4 \pm 2 \mathrm{~d})$ than in autumn $(15 \pm 13 \mathrm{~d})$ due to a time-minimization strategy for breeding, and they showed considerable between-individual variation in the timing of the autumn migration, probably due to differences in the timing of breeding. Gulls that made at least two round trips exhibited high flexibility in spring migration timing, suggesting a stronger influence of local environment conditions over endogenous controls. There was also high route flexibility among different years, probably due to variations in meteorological or habitat conditions at stopover sites. Relict Gulls stayed for a remarkably long time $(234 \pm 17 \mathrm{~d})$ on their major wintering grounds in Bohai Bay and Laizhou Bay, between which there were notable dispersals. Pre-breeding dispersals away from the breeding area were distinct, which seemed to be a strategy to cope with the degradation of breeding habitat at Hongjian Nur. Overwhelming lake shrinkage on the breeding ground and at stopover sites and loss of intertidal flats on the wintering grounds are regarded as the main threats to Relict Gulls. It's crucial to make protection administrations aware of the great significance of key sites along migration routes and to promote the establishment of protected areas 


\section{INTRODUCTION}

The Relict Gull (Larus relictus) breeds at scattered sites on arid lakes in eastern Kazakhstan, Mongolia and the Russian Far East, but most breeding colonies, known as the Ordos subpopulation, occur in Shaanxi and Inner Mongolia in northern China (He et al., 2002; BirdLife International, 2016). The global population of the Relict Gull has been estimated at 10,00019,999 but has fluctuated considerably due to human disturbance and lake degradation at breeding sites as well as habitat loss on the wintering grounds in East Asia (He et al., 2005; BirdLife International, 2016). Therefore, the Relict Gull is recognized as vulnerable on the IUCN Red List (BirdLife International, 2016) and is listed among the First Class State Protected Wildlife in China.

Confirmed as a valid species as recently as 1971 (Auezov, 1971), the Relict Gull is one of the least known birds. Most previous research has focused on its breeding colonies, and only occasional winter records have been documented in Japan, Korea, Vietnam, eastern China and Hong Kong (Duff, Bakewell \& Williams, 1991; He et al., 2002; Olsen \& Larsson 2004). Since late 1990s, legflag marking and resighting has indicated that the Bohai Bay of China is an important wintering ground for the Ordos sub-population (He et al., 2002), and later field surveys have confirmed that Bohai Bay supports a considerable wintering population (Liu et al., 2006). However, the detailed migratory routes, stopover sites and wintering range of the Relict Gull remain poorly understood (Liu et al., 2006; BirdLife International, 2016).

Because most Relict Gulls breed at Hongjian Nur in northern China (Xiao et al., 2008) and winter on Bohai Bay, the migration routes of the species probably cover vast areas of the InnerMongolian Plateau, where several arid lakes may serve as stopover sites. Over the past several decades, the Inner-Mongolian Plateau has experienced increasingly significant lake shrinkage resulting from climate change and the increasing exploitation of underground minerals and groundwater resources (Tao et al., 2015). On the coast of eastern China, the potential wintering grounds of the Relict Gull, ongoing tidal land reclamation has had continuous, serious impacts on waterbirds (Yang et al., 2011; Ma et al., 2014), so the species may face serious threats from habitat loss along its migration routes. Identifying key stopover sites and determining the 
wintering range of the Relict Gull is critical for the conservation of this vulnerable species and would provide basic information to improve our understanding of the impacts of habitat loss on bird migration strategies.

We deployed Platform Transmitter Terminals (PTTs) on Relict Gulls breeding in Hongjian Nur in northern China to determine their migration routes, stopover sites, wintering grounds and seasonal dispersal. Based on satellite tracking data, we compared between- and within-individual variation in migration timing and routes and examined repeat autumn and spring journeys to analyze flexibility in individual migration behavior. We also conducted extensive ground surveys along the migration routes of the species to better understand the status of the Relict Gull population and its habitat at major stopover sites and on its wintering grounds.

\section{METHODS}

Study site

Hongjian Nur $\left(38^{\circ} 13^{\prime}-39^{\circ} 27^{\prime} \mathrm{N}, 109^{\circ} 42^{\prime}-110^{\circ} 54^{\prime} \mathrm{E}\right)$ is located at the junction of the Mu Us Desert and the Ordos Plateau, approximately $60 \mathrm{~km}$ south of the city Ordos in Inner Mongolia, China, at an elevation of $1200 \mathrm{~m}$. It used to be the largest desert freshwater lake in China, but the total area of the lake has been shrinking, from $55 \mathrm{~km}^{2}$ in 1997 to $32 \mathrm{~km}^{2}$ in 2013 , due to drought and overexploitation of the groundwater. Hongjian Nur is an important breeding ground and stopover site for many waterbird species (Xiao et al., 2010), and it has been protected as a county-level nature reserve since 1997. Breeding Relict Gulls were first recorded on the islands of Hongjian Nur in 2000, and the breeding population has fluctuated considerably due to habitat changes in recent years, with the number of nests reaching a maximum of ca. 7700 in 2011 (Miao, 2014). In this study, Relict Gulls were captured on the largest nesting island $\left(39^{\circ} 8.3^{\prime} \mathrm{N}\right.$, $\left.109^{\circ} 52 \cdot 2^{\prime} \mathrm{E}\right)$.

\section{Gull capture and transmitter attachment}

We captured 11 adult Relict Gulls (two in 2007, five in 2008, and four in 2010) on their nesting island using monofilament leg nooses; all capture attempts were made after the chicks had 
86

87

fledged to avoid disturbing the breeding activities. Upon capture, the gulls were placed in individual cloth bags and promptly processed, during which we recorded the mass, wing length and tarsus length of each gull.

The gulls were tagged with 9-g solar-powered PTTs (PTT-100, Microwave Telemetry, Inc., Columbia, MD, USA) in 2007 and with 12-g solar-powered PTTs (Model 12 GS, Northstar Science and Technology, LLC, VA, USA) in 2008 and 2010, using a Teflon ribbon back harness; the combined weight of the PTT and harness was $1.6-2.6 \%$ of the gull's body mass. The gulls were also marked with orange Darvic-type leg flags. All gulls were released near their capture locations as soon as possible after processing.

\section{Satellite telemetry locations and spatial analysis}

The PTTs were tracked using the following transmitting cycles: $10 \mathrm{~h}$ on and $47 \mathrm{~h}$ off in $2007,8 \mathrm{~h}$ on and $15 \mathrm{~h}$ off in 2008, and $8 \mathrm{~h}$ on and $23 \mathrm{~h}$ off 2010, and the Doppler-derived PTT location information was received by the CLS/Service Argos satellite tracking system (Argos, 2007). Location classes (LC) ranged from zero to three, which reflected location accuracy (Argos, 2007), and 1-sigma error radii of $>1,000 \mathrm{~m}, 350-1000 \mathrm{~m}, 150-350 \mathrm{~m}$, and $150 \mathrm{~m}$ were reported for LCs 0, 1, 2 and 3, respectively. Auxiliary LC A, B and Z were not assigned accuracy estimates. We used the Douglas Argos-Filter Algorithm (v. 8.50) to identify and remove implausible auxiliary Doppler locations based on the distance moved, movement rate, and turning angle (Douglas et al., 2012).

Because the PTTs did not transmit continuously, we used the median date between the last point at the previous location and the first point at the new location to calculate timing. If the gap between dates was greater than ten days due to no data or LCs A, B, and Z data received from ARGOS, then timing was not calculated.

We used ArcView GIS (version 3.2; Environmental Systems Research, Redlands, California, USA) to plot the telemetry locations and delineate the migratory routes. Stopover sites were defined as areas where birds moved less than $20 \mathrm{~km}$ during at least a $24-\mathrm{h}$ period, and we used the X-tool extension to calculate the lengths of the migration segments between two adjacent 
113 stopover sites. To determine the wintering range of the Relict Gulls, we pooled the wintering

114 locations and calculated 90\% and 50\% fixed kernel home ranges using a fixed kernel method

115 with least squares cross validation for the smoothing factor (Worton, 1989) in the Animal

116 Movement extension (Hooge \& Eichenlaub, 1997).

\section{Ground surveys}

118 Google Earth 7.1.5.1557 (Google, California, USA) was used to plot stopover sites and wintering

119 locations and to identify potentially important areas based on known habitat requirements.

120 Stopover sites that were heavily used by the tracked gulls were investigated at the time of year

121 when they were most active, and we counted the number of Relict Gulls with the aid of $8 \times 42$

122 binoculars and $20-60 \times 80-\mathrm{mm}$ spotting scopes and recorded human disturbance and lake

123 shrinkage (Table S1). To monitor the population dynamics on the wintering grounds, we

124 conducted monthly surveys at 37 and 4 wintering locations (Fig. S1), as revealed by satellite

125 tracking, on the Bohai Bay and Laizhou Bay, respectively, from September 2011 to April 2012.

126 During each survey, two teams consisting of two to three members each simultaneously surveyed

127 the wintering locations on Bohai Bay and Laizhou Bay. Counters arrived at specific locations

128 two hours before low tide, and each performed separate counts from the shore on foot.

129 Furthermore, the major habitat threats at each wintering location were recorded (Table S2).

130 Individual migration variation and data analysis

131 With individual as a factor in ANOVA, we compared between- and within-individual variation

132 in migration timing and route (Vardanis et al., 2011; Stanley et al., 2012). Based on the satellite

133 tracking results, Relict Gull migration was predominantly longitudinal, and the routes were

134 relatively short; $114^{\circ} \mathrm{E}$ marked the midline of the routes (see Results) and was a suitable

135 reference to determine the spatial variation in migration. Therefore, we examined four variables:

136 departure date, latitude crossing $114^{\circ} \mathrm{E}$, arrival date, and migration duration. For gulls with at

137 least two round trips, we also calculated the repeatability (intra-individual correlation coefficient;

138 Lessells \& Boag, 1987) of migration timing and route.

139 We used $t$-tests to examine the within-route and autumn and spring differences in migration 
140

141

142

segments, and we used paired $t$-tests to compare the individual autumn and spring migration distances. In cases where individuals were tracked for more than one round trip, we used the mean values of the repeated seasons for each of these individuals in the comparison.

All statistical analyses were performed using SPSS software (version 22.0, IBM 2013). Results were given as mean $\pm \mathrm{SD}$ with a significance level of 0.05 based on two-tailed tests.

\section{Ethical note}

All data collected as part of this study were approved by National Bird Banding Center of China (No. NBBC20070512). Field work was approved by State Forestry Administration (No. 33 Forestry Protection [2002]).

\section{RESULTS}

In 2007, the PTT signals of two of the 11 tracked Relict Gulls (G1 and G2) were lost before the onset of autumn migration. For the remaining nine individuals (G3-G11), we obtained data of 20 complete autumn migration journeys and 13 complete spring migration journeys, including one individual with one round trip, two individuals with two round trips and two individuals with four round trips (Table 1). The complete dataset for these nine individuals contained 9151 locations; 40.8\% were high quality (LC 1-3). The average number of locations recorded per individual was $1017 \pm 976(\mathrm{n}=9)$, and the average number of locations per day per individual was $1.7 \pm 0.7(\mathrm{n}=9$, Table S3).

\section{Migration timing}

During the autumn migration, Relict Gulls departed their breeding grounds on July $31^{\text {st }}$ (range $=$ July $18^{\text {th }}-$ September $2^{\text {nd }}, n=20$ ), with $80 \%$ of individuals leaving between July $21^{\text {st }}$ and August $3^{\text {rd }}$. After migrating for $15 \pm 13$ days (range $=1-42$ days, $\mathrm{n}=20$ ), gulls arrived at their wintering grounds on August $16^{\text {th }}\left(\right.$ range $=$ July $22^{\text {nd }}-$ September $24^{\text {th }}, \mathrm{n}=20$; Table 1 ) and remained for $234 \pm 17$ days (range $=206-255$ days, $n=13$ ), an extremely long duration. The gulls departed their wintering grounds on April $5^{\text {th }}\left(\right.$ range $=$ March $31^{\text {st }}-$ April $\left.10^{\text {th }}, \mathrm{n}=13\right)$ and arrived at their breeding grounds on April $9^{\text {th }}$ (range $=$ April $3^{\text {rd }}-$ April $15^{\text {th }}, \mathrm{n}=13$ ) after migrating for $4 \pm 2$ days (range $=1-7$ days, $n=13$; Table 1 ). 


\section{Migration routes}

Unlike that of most bird species, Relict Gull migration constituted a far greater shift in longitude than latitude $\left(\Delta\right.$ longitude $=9.4 \pm 0.7^{\circ}, \Delta$ latitude $=1.7 \pm 0.5^{\circ}, \mathrm{n}=29 ;$ Fig. 1 ). During the autumn migration, most gulls (six of the nine gulls in 13 of 20 autumn migration seasons) took inverted V-shaped routes; after departing from Hongjian Nur, they flew northeast across the InnerMongolian Plateau and rested at wetland complexes formed by Chahan Nur, Xiyan Nur, and Anguli Nur, etc., at the border between Inner Mongolia and Hebei Province (Fig. 1). After refueling at these wetland complexes, the gulls headed southeast and finally arrived at their wintering grounds on the coast of eastern China. In the remaining seven seasons, the gulls took quite direct routes across Shanxi and Hebei Province.

During the spring migration, gulls used similar routes as in autumn, but most (in 11 of the 13 seasons) took the more direct routes. Thus, Relict Gulls generally followed a clockwise migration loop (Fig. 1).

\section{Variation in and repeatability of migration timing and routes}

Individual had a significant effect on all timing variables in autumn (Table 2), but there was no effect on the timing of the spring migration. Tests of within-individual repeatability indicated that migration variables were more repeatable in autumn than in spring and in timing than in route (Table 3). High repeatability (One-way ANOVA, $F_{3,10}=17.42, p<0.001, r=0.80$ ) was found in the winter arrival date, for which individuals differed between years by an average of \pm $8 \mathrm{~d}$, and the duration of the autumn migration was also highly repeatable (One-way ANOVA, $F_{3 \text {, }}$ $\left.{ }_{10}=14.28, p=0.01, r=0.76\right)$, with an average difference of $\pm 7 \mathrm{~d}$ between years.

\section{Stopover sites and distances}

After departing from Hongjian Nur, the gulls traveled $839 \pm 116 \mathrm{~km}(\mathrm{n}=20$, range $=670-1040$ $\mathrm{km}$ ) and made a diverse number of stopovers (average $=1.4$, range $=0-5$ ); in 17 of the 20 autumn migration journeys, all nine tracked gulls made two or fewer stopovers before reaching their wintering grounds. The gulls traveled $350 \pm 216 \mathrm{~km}$ (range $=30-810 \mathrm{~km}, \mathrm{n}=48)$ per migration segment (Table 1), but in the journeys with two or more stopover sites, the first and last migration segments $(401 \pm 73 \mathrm{~km}, \mathrm{n}=18)$ were significantly longer than the remaining 
segments $(66 \pm 31 \mathrm{~km}, \mathrm{n}=14 ; t$-tests, $t=16.13, d f=30, p<0.001)$, indicating that the stopover sites were concentrated in the middle portion of the route (Fig. 1). Gulls used the Chahan Nur, Xiyan Nur and Anguli Nur wetland complexes at the border between Inner Mongolia and Hebei Province, where the gulls stayed for a total of 151 days $(66.2 \%$ of the total duration) in 14 of the 28 autumn migration journeys (Table 4).

In spring, the gulls traveled $738 \pm 109 \mathrm{~km}(\mathrm{n}=13$, range $=670-1050 \mathrm{~km})$, and most (four of the five gulls in 10 of the 13 spring migration journeys) migrated directly to their breeding ground at Hongjian Nur without a stopover (Table 1).

On an individual basis, there was no significant difference between the autumn and spring migration distances (paired $t$-test, $t=1.08, p=0.34, \mathrm{n}=5$ individuals), but the migration segments in spring $(599 \pm 187 \mathrm{~km}, \mathrm{n}=16)$ were significantly longer than those in autumn $(t$-test, $t=4.136, d f=62, p<0.001)$.

\section{Wintering grounds and wintering dispersal}

The wintering grounds of the Relict Gulls stretched along the coast from Changli $\left(39.480^{\circ} \mathrm{N}\right.$, $\left.119.257^{\circ} \mathrm{E}\right)$ in Hebei Province south to Jimo $\left(36.446^{\circ} \mathrm{N}, 120.798^{\circ} \mathrm{E}\right)$ in Shandong Province (Fig. 2). The gulls wintered almost exclusively on Bohai Bay and Laizhou Bay in the Bohai Sea, except G11, who stayed on the Bay of the Yellow Sea in January 2011. The Bohai Bay wintering ground ranged from Leting in Hebei Province south to Zhanhua in Shandong Province, and the Laizhou Bay wintering ground was from Kenli south to Shouguang in Shandong Province. The core area of the wintering home range covered the coast in Tianjin, Huanghua and Luannan in Hebei Province and Haixing, Wudi and Kenli in Shandong Province and was $1380 \mathrm{~km}^{2}$ in size (50\% fixed kernel, Fig. 2).

For all 20 autumn migration journeys, all nine gulls arrived at Bohai Bay first but then exhibited distinct dispersal patterns between Bohai Bay and Laizhou Bay in 12 of the 13 wintering seasons, although in one season, G4 wintered solely on Bohai Bay. The gulls migrated from Bohai Bay to Laizhou Bay on $28^{\text {th }}$ December (range $=$ December $1^{\text {th }}-$ February $4^{\text {th }}, \mathrm{n}=12$ ), and in nine $(75 \%)$ of the 12 seasons, the gulls returned to Bohai Bay on March $13^{\text {th }}$ (range $=$ February $16^{\text {th }}-$ April $4^{\text {th }}$, Fig. 2). In one season, G11 stayed at Laizhou Bay until departure for spring migration, and in the remaining two seasons, insufficient data prevented us from determining if the gulls returned to Bohai Bay. Furthermore, G11 exhibited complex round-trip 
226 dispersal in Bohai Bay, Laizhou Bay and the Coast of the Yellow Sea in the 2010-2011 227 wintering season.

228 A maximum of 11,800 Relict Gulls were recorded on Bohai Bay and Laizhou Bay in February during the 2011-2012 wintering season. Ground surveys also indicated that the number of wintering Relict Gulls on Laizhou Bay gradually increased each month and peaked at 6,500 in February, confirming the dispersal pattern between Bohai Bay and Laizhou Bay revealed by satellite tracking (Fig. 3).

Pre-breeding dispersal

Of the five Relict Gulls back to breeding ground, four showed novel pre-breeding dispersal from Hongjian Nur to the west, north or northeast in nine of the 13 breeding seasons. Upon arriving at Hongjian Nur during the spring migration, Relict Gulls refueled there for $4 \pm 1$ days (range = 2 7 days, $\mathrm{n}=9$ ) and then traveled $204 \pm 146 \mathrm{~km}($ range $=100-540 \mathrm{~km}, \mathrm{n}=9$ ) to the following areas: a wetland complex in Ordos (where three gulls stayed for 42 days in four seasons, one stayed for a whole breeding season), Yellow River stretch in Baotou (two gulls stayed for 36 days in three seasons), a wetland complex in Tuoketuo (one gull stayed for 20 days in one season) and Wulanhushaohaizi (one gull stayed for 13 days in one season, Fig. 4). The gulls (G4, G5 and G7) exhibited low fidelity to the pre-breeding dispersal areas from year to year. After dispersal for $17 \pm 6$ days (range $=7-27$ days, $n=8$ ), most of the Relict Gulls, except G11, returned to their breeding grounds at Hongjian Nur on April $30^{\text {th }}$ (range $=$ April $27^{\text {th }}-$ May $3^{\text {th }}$ ).

\section{DISCUSSION}

\section{Migration timing, routes and stopover sites}

This report is the first description of the migration details of the Relict Gull, a vulnerable species that heavily relies on arid lakes in Asia. Coincident with banding recovery and field observation results (He et al., 2002; Liu et al., 2006), the adult Relict Gulls from the Ordos sub-population mainly migrate across the Inner-Mongolia Plateau and winter on the coast of Bohai Sea. The migration of the Relict Gull is notable for its extensive change in longitude relative to latitude, which was also documented in the California Gull Larus californicus and the Pacific Gull Larus pacificus (Woodbury \& Knight, 1951; Pugesek, Diem \& Cordes, 1999), and the species generally exhibits a clockwise loop migration, following relatively shorter and more southward routes in spring compared to autumn to avoid the influence of cold weather (Fig. S2) and to 
257 quickly return to their breeding grounds.

258 A significantly faster migration was revealed in spring (4 $\pm 2 \mathrm{~d})$ than in autumn $(15 \pm 13 \mathrm{~d})$, 259 due to a time-minimization strategy for breeding (Alerstam, 2011). At the extremes in both

260 spring and autumn, there were gulls (G4, G5, G7 and G10) that accomplished their migration in 261 less than one day, with traveling speeds of more than $30 \mathrm{~km} / \mathrm{h}$. Considering that the different 262 transmitting cycle for PTTs in different years resulted in different sampling efficiency and 263 switched off PTTs may cause incomplete sampling especially over a short period, the migration 264 duration might be overestimated. Compared with other Larus species (Zhang et al., 2014), Relict 265 Gulls arrived at their wintering grounds quite early and stayed for extremely long durations, and 266 we suggest this is a response to hostile habitat conditions experienced en route that have resulted 267 from remarkable lake shrinkage on the Inner-Mongolian Plateau (Tao et al., 2015).

\section{Migration variability and repeatability}

269 Relict Gulls exhibited considerable between-individual variation in the timing of the autumn 270 migration, which, although not directly evident from our dataset, might be explained by breeding timing and breeding success. A delayed breeding season (e.g., laying a second clutch after an initial failure) resulted in both delayed departure from the breeding grounds and delayed arrival to the wintering grounds (G8 in 2010, Table 1) due to short stopovers.

Repeated tracking of the same individuals during consecutive years can improve our understanding of spatial and temporal variability and the role of flexibility in animals' migratory behavior (Vardanis et al., 2011). Contrary to most bird migration habits (Vardanis et al., 2011; Stanley et al., 2012; López-López, García-Ripollés \& Urios, 2014), Relict Gulls did not show high repeatability in the timing of spring migration from year to year, which suggests a stronger influence of the local environment conditions than endogenous controls; inclement weather on Bohai Bay and the Inner-Mongolian Plateau may have a particularly profound impact on the onset and arrival date of spring migration (Fig. S2). However, gulls exhibited highly repeatable winter arrival dates, which might be explained by higher predictability of environmental conditions along the migration routes at the end of the summer compared to just before the onset of spring migration (López-López, García-Ripollés \& Urios, 2014). There was a high degree of flexibility in the routes followed by the same individual in different years, probably due to variations in meteorological conditions (Mellone et al., 2011) or habitat conditions at stopover 287 sites (Table S1). 


\section{Wintering and pre-breeding dispersal}

Our results confirmed that Bohai Bay is important for wintering Relict Gulls (Liu et al., 2006), and we determined that Laizhou Bay is another major wintering ground. The wintering dispersal from Bohai Bay to Laizhou Bay indicates that Relict Gulls may move southward along the coast to avoid hostile weather conditions (Fig. S2) or to follow southward shifts in maritime currents and food sources. Although our tracked adult gulls wintered stably on the coast of the Bohai Sea, there were irregular wintering records further south in Jiangsu, Shanghai, and Hong Kong in China and even in Japan and Vietnam, and most of these individuals were juveniles ( $\mathrm{Su}$ et al., 1998; He et al., 2002). Moreover, banding and recovery records indicate that juveniles may winter from Jinzhou (Liaodong Bay of Bohai Sea) in Liaoning Province southwest to Yimen in Yunnan Province and prolong their stay at Bohai Bay until May (Table S4). We suggest that juvenile Relict Gulls, as revealed in some other Larus species (Pugesek, Diem \& Cordes, 1999; Marques et al., 2009), were distributed over a larger range because they had more time and thus less need to follow the migration route between the breeding and wintering grounds; therefore, juveniles had a greater opportunity to select breeding sites other than their natal site.

Pre-breeding dispersals away from the breeding area were not an individual characteristic since gulls (G4 and G11) that undertook dispersal one year did not necessarily do so in other years (Raw data S1). Moreover, gulls (G4, G5 and G7) used different dispersal areas from year to year (Raw data S1). Pre-breeding dispersal seems to be a strategy to cope with the degradation of breeding habitat at Hongjian Nur by seeking new breeding areas. This is well exemplified by G11 who bred at Hongjian Nur in 2011 and did not engage in pre-breeding dispersal to a distant site, but pursued pre-breeding dispersal west to Ordos and bred there in 2012. Due to lake shrinkage at Hongjian Nur, the number of Relict Gull breeding pairs continuously decreased from ca. 7,700 in 2011 to 4,000 in 2016, but increasing numbers of breeding pairs have recently been discovered in the surrounding wetlands (Ren \& He, 2015). Of the six pre-breeding dispersal areas revealed in this study (Fig. 4), three (the wetland complex in Ordos, Yellow River stretch in Baotou, and Wuliangsuhai) have been confirmed to be breeding areas since 2009 (Miao, 2014; Ren \& He, 2015).

\section{Threats along migration routes}

Ongoing lake shrinkage on the Inner-Mongolian Plateau (Tao et al., 2015) has already profoundly impacted Relict Gulls, whose breeding colonies have been shifting over the past three 
319 decades (He et al., 2005; Ren \& He, 2015). Since the first discovery of Relict Gulls in 1987, the 320 number of breeding pairs at Boerjiang Nur reached a peak of 3,587 in 2000 before dramatically decreasing until the lake was abandoned in 2004 due to lake dried up (Miao, 2014). On the current Hongjian Nur breeding grounds, the number of breeding pairs has decreased since 2011 due to habitat change of the breeding island resulting from lake shrinkage. Currently, Relict Gull breeding colonies tend to scatter and shift to the surrounding lakes (Ren \& He, 2015). As a result, breeding pairs will definitely invest more in nest site competition. Moreover, our ground surveys indicated that most stopover sites for Relict Gulls have faced major human disturbances in the forms of tourism and grazing with varying degrees of fishing, pollution and dredging (Table S1). Lake shrinkage was overwhelming at the stopover sites; Anguli Nur, Huanggai Nur and Saigai Nur were nearly dried up (Table S1). Our results suggest that changes in the quality, quantity and spatial distribution of suitable stopover sites have a profound impact on the migration strategy of the Relict Gull.

Due to rapid economic growth in China, coastal wetlands have been continuously reclaimed during recent decades, causing serious impacts on waterbirds (Yang et al., 2011; Ma et al., 2014). On the wintering grounds of Relict Gulls, 95\% of the surveyed Relict Gull wintering locations (n =37) on Bohai Bay face significant threats. Intertidal mudflat reclamation for aquaculture and harbor and oilfield construction has been found at 70\% of the locations (Table S2). As a result of habitat loss, it is common to find large numbers of Relict Gulls concentrated into a small area on their wintering grounds, which makes the population extremely vulnerable to threats; for example, a serious oil spill could devastate these birds.

Our results revealed the most important sites along the migration routes of Relict Gulls. It is very important to make the local government aware of the great significance of these key sites for Relict Gulls and to promote the establishment of protected areas in these regions. Furthermore, as the species relies heavily on vulnerable arid lakes, the Relict Gull provides an opportunity to understand the degree of phenotypic plasticity in migration in response to environmental change.

\section{ACKNOWLEDGMENTS}

We thank Zhongqiang Wang, Caie Hu and Yongqi Ren for their assistance with the field work. We thank two anonymous reviewers for their valuable comments to improve the manuscript. 


\section{REFERENCES}

352

Alerstam T. 2011. Optimal bird migration revisited. Journal of Ornithology 152(1 Supplement):5-23

Argos. 2007. User Manual. Landover, Maryland: Service Argos, Inc

Auezov EM. 1971. Taxonomic evaluation and systematic status of Larus relictus. Journal of Academy of Science Moscow 50:235-242

BirdLife International. 2016. Species factsheet: Larus relictus. Available at http://datazone.birdlife.org/species/factsheet/relict-gull-larus-relictus $\quad$ (accessed 10 November 2016)

Douglas DC, Rolf W, Sarah CD, Rol K, Martin W, Gil B. 2012. Moderating Argos location errors in animal tracking data. Methods in Ecology and Evolution 3(6):999-1007

Duff DG, Bakewell DN, Williams MD. 1991. The Relict Gull Larus relictus in China and elsewhere. Forktail 6:43-65

He F, Melville D, Xing X, Ren Y. 2002. A review on studies of the Relict Gull Larus relictus. Chinese Journal of Zoology 37:65-70 (in Chinese)

He F, Xing X, Ala T, Ren Y. 2005. The impact of climate change on the breeding population and threats status of Relict Gull. In: Li D, Xu R, eds. Mechanisms of Endangered Species of China and Principles of Conservation. Science Press, Beijing. 291-309 (in Chinese)

Hooge PN, Eichenlaub B. 1997. Animal movement extension to ArcView v. 1.1. Alaska Biological Science Center, U.S. Geological Survey. Anchorage

Lessells CM, Boag PT. 1987. Unrepeatable repeatabilities: a common mistake. Auk 104:116-121

Liu Y, Holt PI, Lei J, Zhang Y, Zhang Z. 2006. Distribution, numbers and age structure of Relict Gull Larus relictus in Bohai Bay, China. Waterbirds 29(3):375-380

López-López P, García-Ripollés C, Urios V. 2014. Individual repeatability in timing and spatial flexibility of migration routes of trans-saharan migratory raptors. Current Zoology 60(5):642-652

Marques PAM, Costa AM, Rock P, Jorge PE. 2009. Age-related migration patterns in Larus fuscus spp. Acta Ethologica 12(2):87-92

Mellone U, López-López P, Liminana R, Urios V. 2011. Weather conditions promote route 
380

flexibility during open ocean crossing in a long-distance migratory raptor. International Journal of Biometerorology 55:463-468

Miao C. 2014. Research and Conservation of Relict Gull. China Forestry Publishing House, Beijing (in Chinese)

Olsen KM, Larsson H. 2004. Helm Identification Guides: Gulls of Eruope, Asia and North America. Christopher Helm, London

Pugesek BH, Diem KL, Cordes CL. 1999. Seasonal movements, migration, and range sizes of subadult and adult Bamforth Lake California Gulls. Waterbirds 22(1):29-36

Ren Y, He F. 2015. Ordos population of Relict Gull shifted to new breeding grounds. Wetland Science \& Management 11(3):63 (in Chinese)

Stanley CQ, MacPherson M, Fraser KC, McKinnon EA, Stutchbury BJM. 2012. Repeat tracking of individual songbirds reveals consistent migration timing but flexibility in route. PLOS ONE 7(7): e40688. doi: 10.1371/journal.pone.0040688

Su HL, Wang H, Lu SC, Wang XM. 1998. A survey of Saunders's Gull and other wintering waterbirds and their habitat status in Jiangsu and Shanghai. In: Studies on Chinese ornithology - Proceedings of the $3^{\text {rd }}$ Ornithological Symposium of Mainland China \& Taiwan, China. Wildbird Society of Taipei, Taiwan (in Chinese)

Tao S, Fang J, Zhao X, Zhao S, Shen H, Hu H, Tang Z, Wang Z, Guo Q. 2015. Rapid loss of lakes on the Mongolian Plateau. Proceedings of the National Academy of Sciences of the United States of America 112(7):2281-2286

Vardanis Y, Klaassen RHG, Strandberg R, Alerstam T. 2011. Individuality in bird migration: routes and timing. Biology Letters 7:502-505

Woodbury AM, Knight H. 1951. Results of the Pacific Gull color-banding project. Condor 53:57-77

Worton B. 1989. Kernel methods for estimating the utilization distribution in home-range studies. Ecology 70:164-168

Xiao H, Wang Q, Wang Z, Hu C, Cai Q. 2010. Analysis on diversity and composition of waterbirds from Hongjiannao wetland, Shaanxi Province. Sichuan Journal of Zoology 29(5):605-608 (in Chinese)

Xiao H, Wang Z, Hu C, Wang Y. 2008. Relict Gull Larus relictus breeding population dynamics and their breeding habitat in Hongjian Nur, Shaaxi Province. Science and Technology 
$411 \quad$ Review 26(14):54-57 (in Chinese)

412 Yang HY, Chen B, Barter M, Piersma T, Zhou C, Li FS, Zhang ZW. 2011. Impacts of tidal land 413 reclamation in Bohai Bay, China: ongoing losses of critical Yellow Sea waterbird staging 414 and wintering sites. Bird Conservation International 21(3):241-259

415 Zhang GG, Liu DP, Hou YQ, Jiang HX, Dai M, Qian FW, Lu J, Ma T, Chen LX, Xing Z, Li FS. 416 2014. Migration routes and stopover sites of Pallas's Gulls Larus ichthyaetus breeding at 417 Qinghai Lake, China, determined by satellite tracking. Forktail 30:104-108 
2012.

\begin{tabular}{|c|c|c|c|c|c|c|c|c|}
\hline \multirow[b]{2}{*}{$\begin{array}{l}\text { Indivi } \\
\text { duals }\end{array}$} & \multicolumn{4}{|c|}{ Autumn migration } & \multicolumn{4}{|c|}{ Spring migration } \\
\hline & $\begin{array}{c}\text { Departure } \\
\text { date }\end{array}$ & Arrival date & $\begin{array}{c}\text { No. of } \\
\text { stopo } \\
\text { vers }\end{array}$ & $\begin{array}{c}\text { Length of migration } \\
\text { segments }(\mathbf{k m})\end{array}$ & $\begin{array}{c}\text { Departure } \\
\text { date }\end{array}$ & Arrival date & $\begin{array}{c}\text { No. of } \\
\text { stopov } \\
\text { ers }\end{array}$ & $\begin{array}{c}\text { Length of migration } \\
\text { segments }(\mathbf{k m})\end{array}$ \\
\hline \multirow[t]{2}{*}{ G3 } & 1 Aug 2008 & 3 Aug 2008 & 0 & 810 & 8 Apr 2009 & 15 Apr 2009 & 1 & $470 / 380$ \\
\hline & $31 \mathrm{Jul} 2009$ & 3 Aug 2009 & 1 & $470 / 420$ & - & - & - & - \\
\hline \multirow[t]{4}{*}{ G4 } & $26 \mathrm{Jul} 2008$ & 1 Sep 2008 & 3 & $400 / 40 / 30 / 420$ & 4 Apr 2009 & 6 Apr 2009 & 0 & 700 \\
\hline & $28 \mathrm{Jul} 2009$ & 27 Aug 2009 & 5 & $290 / 50 / 70 / 50 / 30 / 500$ & 5 Apr 2010 & 9 Apr 2010 & 0 & 690 \\
\hline & 11 Aug 2010 & 11 Sep 2010 & 2 & $440 / 30 / 420$ & 5 Apr 2011 & 12 Apr 2011 & 0 & 680 \\
\hline & 26 Jul 2011 & $6 \operatorname{Sep} 2011$ & 2 & $350 / 90 / 460$ & 6 Apr 2012 & 7 Apr 2012 & 0 & 680 \\
\hline \multirow[t]{5}{*}{ G5 } & 3 Aug 2008 & 19 Aug 2008 & 1 & $440 / 470$ & 31 Mar 2009 & 6 Apr 2009 & 0 & 670 \\
\hline & 18 Jul 2009 & 11 Aug 2009 & 3 & $510 / 80 / 40 / 410$ & 1 Apr 2010 & 3 Apr 2010 & 0 & 710 \\
\hline & $30 \mathrm{Jul} 2010$ & 14 Aug 2010 & 2 & $380 / 90 / 430$ & 8 Apr 2011 & 11 Apr 2011 & 0 & 680 \\
\hline & $27 \mathrm{Jul} 2011$ & 28 Jul 2011 & 0 & 670 & 10 Apr 2012 & 14 Apr 2012 & 0 & 670 \\
\hline & 3 Aug 2012 & 17 Aug 2012 & 1 & $490 / 440$ & - & - & - & - \\
\hline
\end{tabular}




\begin{tabular}{|c|c|c|c|c|c|c|c|c|}
\hline G6 & 2 Aug 2008 & 12 Aug 2008 & 1 & $490 / 470$ & - & - & - & - \\
\hline \multirow[t]{2}{*}{ G7 } & 22 Jul 2008 & 3 Aug 2008 & 2 & $420 / 100 / 370$ & 10 Apr 2009 & 13 Apr 2009 & 1 & $810 / 240$ \\
\hline & $21 \mathrm{Jul} 2009$ & 22 Jul 2009 & 0 & 670 & 2 Apr 2010 & 7 Apr 2010 & 0 & 670 \\
\hline G8 & 2 Sep 2010 & 24 Sep 2010 & 2 & $240 / 120 / 380$ & - & - & - & - \\
\hline G9 & 30 Jul 2010 & 14 Aug 2010 & 1 & $390 / 300$ & - & - & - & - \\
\hline G10 & 13 Aug 2010 & 14 Aug 2010 & 0 & 670 & - & - & - & - \\
\hline \multirow[t]{3}{*}{ G11 } & $26 \mathrm{Jul} 2010$ & 5 Aug 2010 & 2 & $490 / 100 / 300$ & 3 Apr 2011 & 5 Apr 2011 & 1 & $550 / 180$ \\
\hline & $21 \mathrm{Jul} 2011$ & $23 \mathrm{Jul} 2011$ & 0 & 710 & 31 Mar 2012 & 3 Apr 2012 & 0 & 810 \\
\hline & $21 \mathrm{Jul} 2012$ & $23 \mathrm{Jul} 2012$ & 0 & 740 & - & - & - & - \\
\hline
\end{tabular}

420 
421 Table 2: One-way ANOVA results and $p$-values of the effects of an individual on migration

422 timing and route variables for nine Relict Gulls $\left({ }^{*} p<0.05 ;{ }^{* *} p<0.01 ;{ }^{* * *} p<0.001\right)$.

\begin{tabular}{llll}
\hline Variable & df & F & $\boldsymbol{p}$-value \\
\hline Autumn migration & & & \\
Autumn departure date & 8,11 & 6.20 & $0.04^{*}$ \\
Latitude crossing $114^{\circ} \mathrm{E}$ & 8,11 & 1.51 & 0.26 \\
Winter arrival date & 8,11 & 11.76 & $0.000^{* * *}$ \\
Autumn migration duration & 8,11 & 7.72 & $0.01^{*}$ \\
Spring migration & & & \\
Spring departure date & 4,8 & 1.24 & 0.37 \\
Latitude crossing $114^{\circ} \mathrm{E}$ & 4,8 & 3.70 & 0.06 \\
Breeding arrival date & 4,8 & 1.53 & 0.28 \\
Spring migration duration & 4,8 & 0.87 & 0.52 \\
\hline
\end{tabular}

423 
425 Table 3: Repeatability (r) of migration timing and route variables for four Relict Gulls with

426 at least two round trips $\left({ }^{*} p<0.05 ;{ }^{* *} p<0.01 ;{ }^{* * *} p<0.001\right)$.

\begin{tabular}{lllll}
\hline Variable & df & F & $\boldsymbol{r}$ & $\boldsymbol{p}$-value \\
\hline Autumn migration & & & & \\
Autumn departure date & 3,10 & 1.60 & 0.13 & 0.25 \\
Latitude crossing $114^{\circ} \mathrm{E}$ & 3,10 & 1.79 & 0.17 & 0.20 \\
Winter arrival date & 3,10 & 17.42 & 0.80 & $0.000^{* * *}$ \\
Autumn migration duration & 3,10 & 14.28 & 0.76 & $0.01^{*}$ \\
Spring migration & & & & \\
Spring departure date & 3,8 & 0.56 & -0.18 & 0.66 \\
Latitude crossing $114^{\circ} \mathrm{E}$ & 3,8 & 0.98 & 0.13 & 0.27 \\
Breeding arrival date & 3,8 & 0.98 & -0.01 & 0.45 \\
Spring migration duration & 3,8 & 0.23 & -0.37 & 0.88 \\
\hline
\end{tabular}


429 Table 4: Migration stopover sites, stopover frequencies and accumulated days for tracked 430 Relict Gulls breeding at Hongjian Nur in China between 2008-2012.

\begin{tabular}{|c|c|c|c|}
\hline \multirow[b]{2}{*}{ Stopover Sites } & \multicolumn{3}{|c|}{ Stopover } \\
\hline & $\begin{array}{l}\text { Coordinates } \\
\text { (latitude, longitude) }\end{array}$ & $\begin{array}{l}\text { Frequency } \\
\text { (No. migration } \\
\text { journeys) }\end{array}$ & $\begin{array}{l}\text { Accumulated } \\
\text { Duration } \\
\text { (No. days) }\end{array}$ \\
\hline \multicolumn{4}{|l|}{ Autumn migration } \\
\hline Chahai Nur & $41.462^{\circ} \mathrm{N}, 113.901^{\circ} \mathrm{E}$ & 6 & 105 \\
\hline Xiyan Nur & $41.522^{\circ} \mathrm{N}, 114.221^{\circ} \mathrm{E}$ & 4 & 26 \\
\hline Anguli Nur & $41.289^{\circ} \mathrm{N}, 114.431^{\circ} \mathrm{E}$ & 4 & 20 \\
\hline Cetian Reservoir & $39.980^{\circ} \mathrm{N}, 113.677^{\circ} \mathrm{E}$ & 1 & 14 \\
\hline Xiahewan Reservoir & $39.750^{\circ} \mathrm{N}, 114.300^{\circ} \mathrm{E}$ & 1 & 13 \\
\hline Kangbu Nur & $41.273^{\circ} \mathrm{N}, 113.890^{\circ} \mathrm{E}$ & 2 & 12 \\
\hline \multicolumn{4}{|l|}{ Huanggai Nur } \\
\hline$\&$ Sangai Nur & $41.350^{\circ} \mathrm{N}, 114.726^{\circ} \mathrm{E}$ & 3 & 11 \\
\hline \multicolumn{4}{|l|}{ Wulanhushaohaizi } \\
\hline \& Baiyin Nur & $41.524^{\circ} \mathrm{N}, 113.270^{\circ} \mathrm{E}$ & 1 & 10 \\
\hline Hanhaizi & $41.462^{\circ} \mathrm{N}, 113.523^{\circ} \mathrm{E}$ & 1 & 7 \\
\hline Huangqihai & $40.830^{\circ} \mathrm{N}, 113.280^{\circ} \mathrm{E}$ & 2 & 6 \\
\hline Daihai & $40.583^{\circ} \mathrm{N}, 112.757^{\circ} \mathrm{E}$ & 1 & 2 \\
\hline Yanghe Reservoir & $40.543^{\circ} \mathrm{N}, 115.106^{\circ} \mathrm{E}$ & 1 & 1 \\
\hline Dongyulin Reservoir & $39.361^{\circ} \mathrm{N}, 112.623^{\circ} \mathrm{E}$ & 1 & 1 \\
\hline \multicolumn{4}{|l|}{ Spring migration } \\
\hline \multicolumn{4}{|l|}{ Wulanhushaohaizi } \\
\hline \& Baiyin Nur & $41.524^{\circ} \mathrm{N}, 113.270^{\circ} \mathrm{E}$ & 1 & 6 \\
\hline Shuangrushan Reservoir & $38.538^{\circ} \mathrm{N}, 112.607^{\circ} \mathrm{E}$ & 1 & 1 \\
\hline Dangyangqiao Reservoir & $40.036^{\circ} \mathrm{N}, 111.625^{\circ} \mathrm{E}$ & 1 & 1 \\
\hline
\end{tabular}




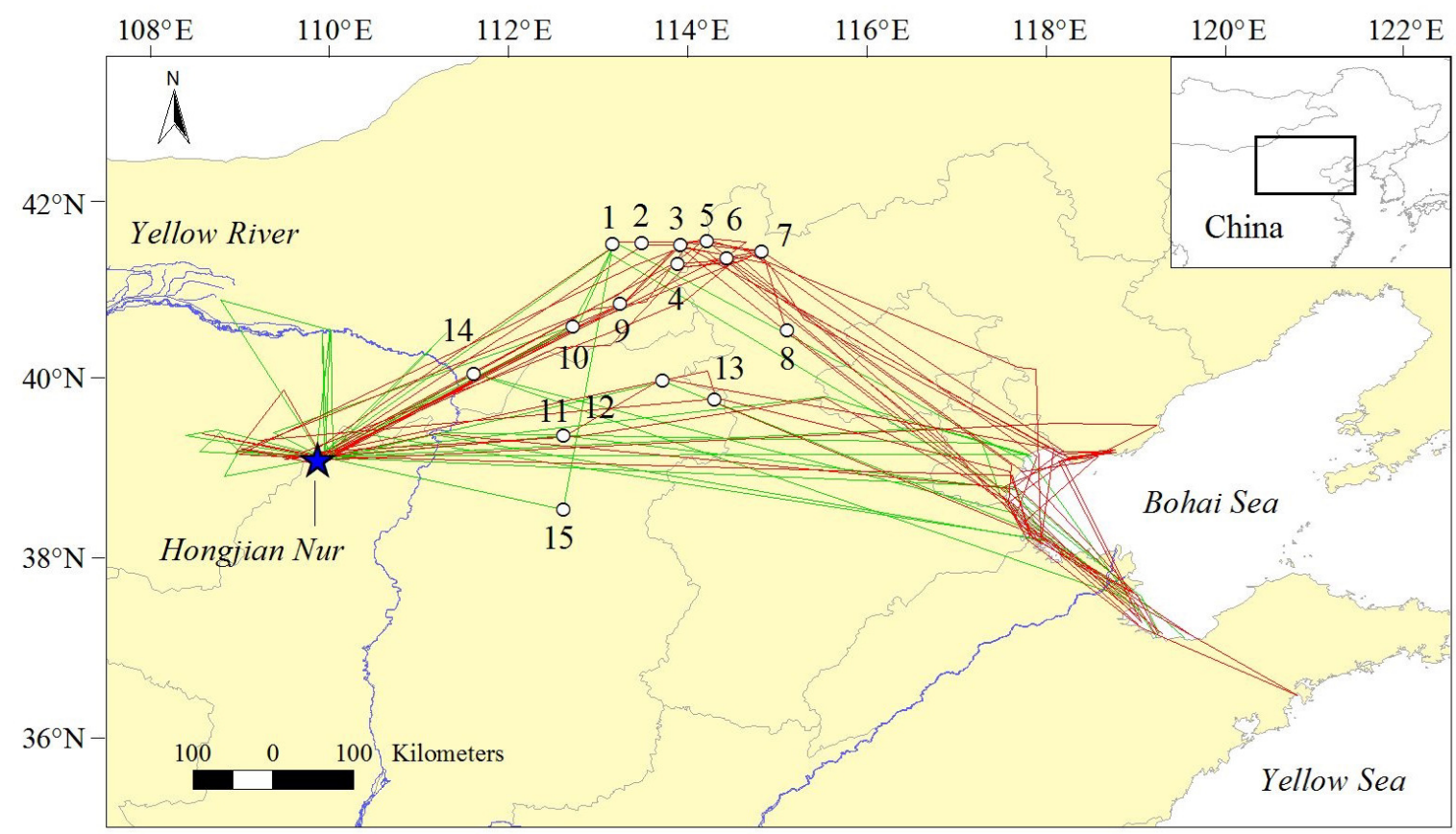

Figure 1: Relict Gull migration routes and stopover sites determined by satellite tracking during autumn (red lines) and spring (green lines) journeys from 2008-2012.

1-Wulanhushaohaizi \& Baiyin Nur, 2-Hanhaizi, 3-Chahan Nur, 4-Kangbo Nur, 5-Xiyan Nur, 6Anguli Nur, 7-Huanggai Nur \& Sangai Nur, 8-Yanghe Reservoir, 9-Huangqihai, 10-Daihai, 11- 


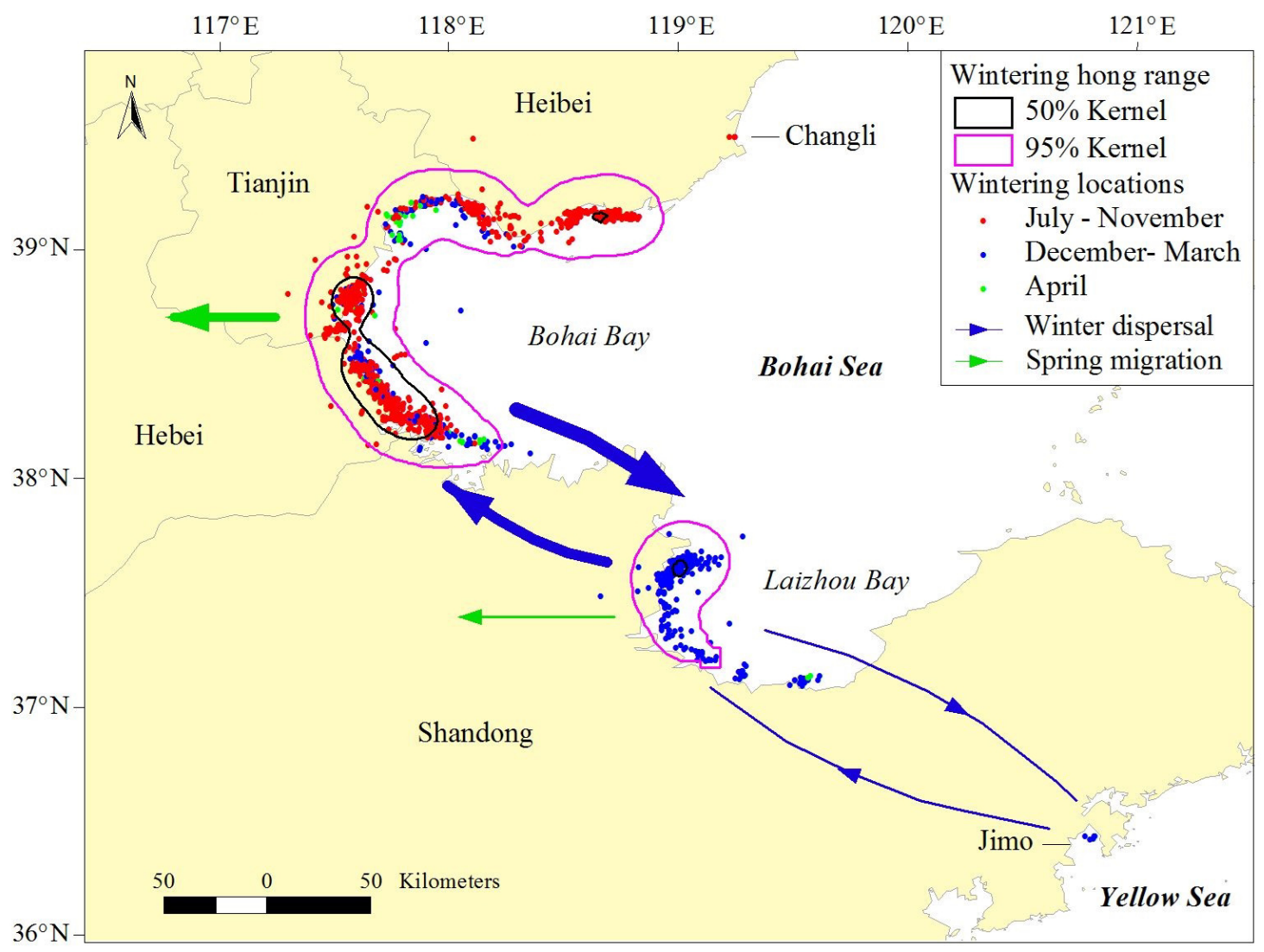

Figure 2: Wintering home range and wintering dispersal of satellite-tracked Relict Gulls on Bohai Bay and Laizhou Bay from 2008-2012.

444 The size of the arrows roughly indicates the number of dispersal gulls. 


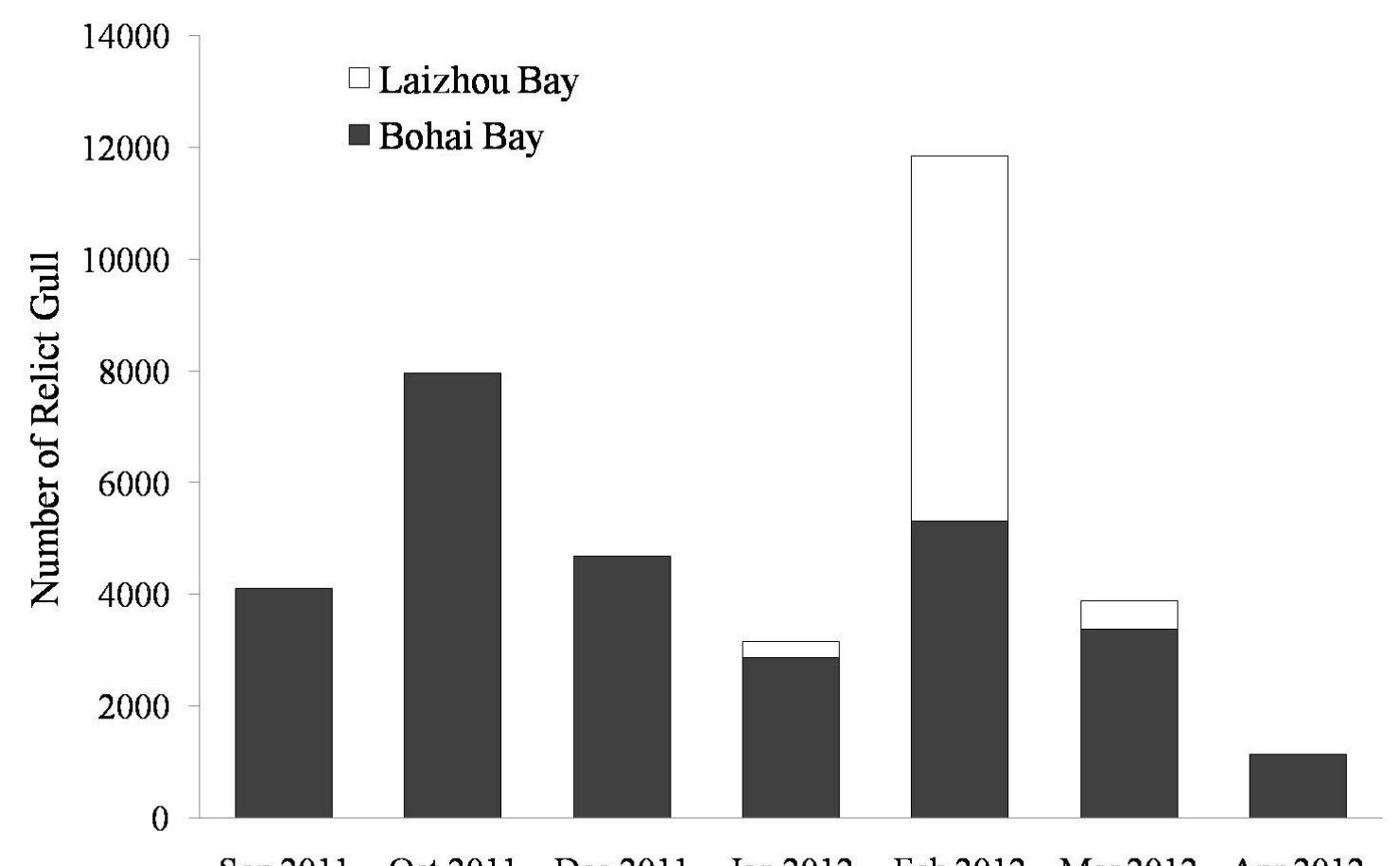

446

447 Figure 3: Number of wintering Relict Gulls on Bohai Bay and Laizhou Bay by month from $448 \quad$ 2011-2012. 


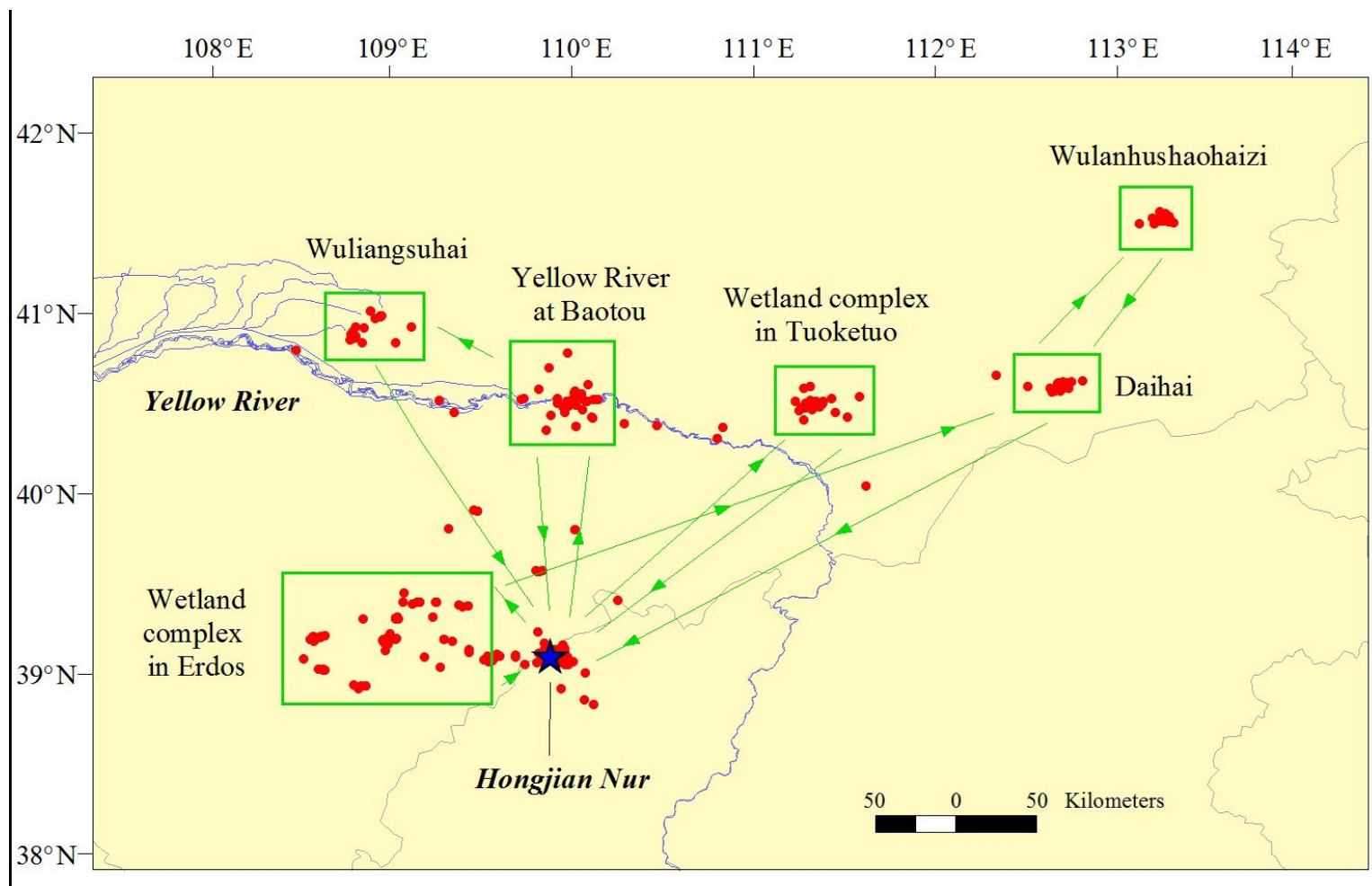

Figure 4: Pre-breeding dispersal sites and direction of satellite-tracked Relict Gulls after 